\title{
Abnormal Carbohydrate Metabolism in Chronic Renal Failure
}

\author{
THE POTENTIAL ROLE OF ACCELERATED GLUCOSE PRODUCTION, \\ INCREASED GLUCONEOGENESIS, AND IMPAIRED GLUCOSE DISPOSAL
}

\author{
Sheldon Rubenfeld and Alan J. Garber, Division of Endocrinology and \\ Metabolism, Departments of Medicine and Cell Biology, Baylor College of \\ Medicine, Houston, Texas 77030
}

\begin{abstract}
A B S T RACT To delineate the potential role of disordered glucose and glucose-precursor kinetics in the abnormal carbohydrate metabolism of chronic renal failure, alanine and glucose production and utilization and gluconeogenesis from alanine were studied in patients with chronic compensated renal insufficiency and in normal volunteers. With simultaneous primed injection-continuous infusions of radiolabeled alanine and glucose, rates of metabolite turnover and precursor-product interrelationships were calculated from the plateau portion of the appropriate specific activity curves. All subjects were studied in the postabsorption state. In 13 patients with chronic renal failure (creatinine $=10.7 \pm 1.2 \mathrm{mg} / 100 \mathrm{ml} ;$ mean $\pm \mathrm{SEM}$ ), glucose turnover was found to be $1,035 \pm 99.3 \mu \mathrm{mol} /$ min. This rate was increased $56 \%(P=0.003)$ over that observed in control subjects $(664 \pm 33.5 \mu \mathrm{mol} / \mathrm{min})$. Alanine turnover was $474 \pm 96.0 \mu \mathrm{mol} / \mathrm{min}$ in azotemic patients. This rate was $191 \%$ greater $(P=0.007)$ than the rate determined in control subjects $(163 \pm 19.4$ $\mu \mathrm{mol} / \mathrm{min})$. Gluconeogenesis from alanine and the percent of glucose production contributed by gluconeogenesis from alanine were increased in patients with chronic renal failure (192\% and $169 \%$, respectively) as compared to controls $(P<0.05$ for each). Alanine utilization for gluconeogenesis was increased from 40.2 $\pm 3.86 \mu \mathrm{mol} / \mathrm{min}$ in control subjects to $143 \pm 39.0$ $\mu \mathrm{mol} / \mathrm{min}$ in azotemic patients $(P<0.05)$. The percent of alanine utilization accounted for by gluconeogenesis was not altered in chronic renal insufficiency. In nondiabetic azotemic subjects, mean fasting glucose and
\end{abstract}

Dr. Garber is an investigator at the Howard Hughes Medical Institute.

Received for publication 7 October 1977 and in revised form 8 February 1978. immunoreactive insulin levels were increased $24.3 \%$ $(P=0.005)$ and $130 \%(P=0.046)$, respectively.

These results in patients with chronic renal failure demonstrate $(a)$ increased glucose production and utilization, $(b)$ increased gluconeogenesis from alanine, $(c)$ increased alanine production and utilization, and $(d)$ a relative impairment to glucose disposal. We conclude that chronic azotemia is characterized by increased rates of glucose and glucose precursor flux and by a relative impairment to glucose disposal. These findings may suggest an underlying hepatic and peripheral insensitivity to the metabolic action of insulin in patients with chronic renal insufficiency.

\section{INTRODUCTION}

Disordered carbohydrate metabolism is widely recognized in patients with chronic renal failure (1). These abnormalities most commonly include previously unrecognized carbohydrate intolerance in greater than $50 \%$ of azotemic individuals $(2,3)$ and even overt fasting hyperglycemia $(3,4)$. However, the development of spontaneous hypoglycemia has also been reported $(5,6)$. On the other hand, an amelioration of the diabetic state with decreasing insulin requirements is a well-known clinical concomitant of advancing renal failure in patients with previously established diabetes mellitus (7).

Recent work in patients with diabetes mellitus has suggested that an inappropriate and excessive rate of glucose production may function as an important determinant of the degree of hyperglycemia (8). Additionally, increased gluconeogenesis from a variety of precursors such as alanine, the principal gluconeogenic amino acid, has been demonstrated in patients with diabetes mellitus $(9,10)$. Elevated rates of alanine 
formation and release may have been described in skeletal muscle of chronically uremic rats (11). Increased hepatic gluconeogenesis has been observed in the acutely uremic rat (12) and in rat liver slices incubated in serum obtained from uremic patients (13).

In light of these data, investigations of glucose and glucose-precursor kinetics were performed in patients with chronic renal insufficiency. Turnover rates of alanine and glucose were determined in chronically azotemic patients and in normal control subjects with simultaneous primed injection-continuous infusions of $\left[\mathrm{U}-{ }^{14} \mathrm{C}\right]$ alanine and $\left[2-{ }^{3} \mathrm{H}\right]$ glucose. Alanine-glucose, precursor-product interrelationships were assessed and compared in the two groups. The roles of accelerated glucose flux, of increased gluconeogenesis from alanine, and of impaired glucose disposal in the abnormal carbohydrate metabolism of chronic renal failure are discussed.

\section{METHODS}

10 healthy adults ( 5 men and 5 women) and 13 nondialyzed patients with chronic renal failure ( 11 men and 2 women) were studied after obtaining informed consent in writing. All control subjects were within $10 \%$ of their desirable body weight (Metropolitan Life Insurance Co. tables), and they ranged in age from 22 to $36 \mathrm{yr}(25.8 \pm 1.29 \mathrm{yr}$; mean \pm SENi). Glucose tolerance was normal as determined by standard 5-h glucose tolerance testing interpreted by the criteria of Fajans and Conn (14). Routine screening blood chemistries, hemograms, and urinalyses were within normal limits as were tests of adrenal and thyroid function.

The clinical data pertaining to the patients with chronic renal failure are presented in Table I. Presumptive etiologies (diagnoses) for renal failure were based upon the following criteria: chronic glomerulonephritis, biopsy and(or) a history of nephrotic syndrome in a nondiabetic patient; diabetic nephropathy, insulin-dependent mellitus of greater than $10 \mathrm{yr}$ duration; obstructive uropathy, chronic lower urinary tract obstruction with bilateral hydronephrosis; nephrosclerosis, severe, inadequately treated hypertension of greater than 10 yr duration before the onset of renal failure; and chronic renal failure of unknown etiology, no specific etiology could be found. Mean weight $(73.9 \pm 3.4 \mathrm{~kg})$ of the azotemic patients was not significantly different from the value for the control subjects $(65.6 \pm 2.7 \mathrm{~kg})$. Body surface area, calculated as an estimate of lean body mass, was not significantly different in the patients with chronic renal failure $\left(1.84 \pm 0.05 \mathrm{~m}^{2}\right)$ when compared to the normal volunteers $\left(1.76 \pm 0.04 \mathrm{~m}^{2}\right)$. In the azotemic subjects, mean blood urea nitrogen, creatinine, hematocrit, and albumin were $99.8 \pm 8.2 \mathrm{mg} / 100 \mathrm{ml}, 10.7$ $\pm 1.2 \mathrm{mg} / 100 \mathrm{ml}, 27 \pm 1 \%$ and $3.5 \pm 0.2 \mathrm{~g} / 100 \mathrm{ml}$, respectively. None of the patients had the nephrotic syndrome $(24 \mathrm{~h}$ protein excretion $>3.0 \mathrm{~g}$ ) or peripheral edema at the time of the study. All patients were maintained on a 2 -g sodium, 2 -g potassium, 40-g high biologic value protein diet made isocaloric to include $300 \mathrm{~g}$ carbohydrate for at least 3 days before the study. The patients were all normokalemic and not acidotic at the time of the study. Medications included varying dosages of dihydrotachysterol, phosphate binders, and sodium citrate solution. Patients taking additional medications required for the management of associated conditions were included in this study only if these medications were known not to interfere with carbohydrate metabolism. Three patients were known to be diabetic before the onset of renal failure; patient S. B. was taking insulin, patient S. P. was taking chlorpropamide. Medications were omitted the morning of the study.

Previously described isotope dilution methodology was modified slightly for the present study (15). After a 12-hr overnight fast, short plastic catheters were inserted in the antecubital veins, bilaterally. $30 \mathrm{~min}$ later, base-line blood samples were withdrawn and a priming intravenous injection of $\left[2-{ }^{3} \mathrm{H}\right]$ glucose $(0.1 \mu \mathrm{Ci} / \mathrm{kg})$ and $\left[\mathrm{U}-{ }^{14} \mathrm{C}\right]$ alanine $(0.1$

TABLE I

Clinical Data of Azotemic Patients Studied*

\begin{tabular}{lcccclcrcr}
\hline Patient & Age & Sex & $W_{t}$ & $\begin{array}{c}\text { Surface } \\
\text { area }\end{array}$ & Diagnosis & Hct & BUN & Creat & Alb \\
\hline & $y r$ & & $k g$ & $m^{2}$ & & $\%$ & $m g / 100 m l$ & $m g / 100 m l$ & $g / l(0) m l$ \\
R. S. & 22 & M & 72 & 1.83 & CGN & 27 & 89 & 13.0 & 2.5 \\
S. B. & 22 & M & 90 & 1.95 & DN & 21 & 140 & 19.9 & 1.7 \\
J. P. & 35 & M & 58 & 1.61 & CRFUE & 22 & 149 & 12.3 & 4.2 \\
W. M. & 37 & M & 81 & 2.02 & NSC & 26 & 82 & 11.8 & 3.4 \\
A. G. & 42 & M & 99 & 2.28 & CGN & 27 & 91 & 10.2 & 4.4 \\
D. F. & 43 & M & 76 & 1.96 & CRFUE & 25 & 120 & 15.7 & 4.1 \\
R. V. & 51 & M & 72 & 1.89 & OU & 29 & 41 & 7.0 & 3.2 \\
M. T. & 61 & M & 54 & 1.52 & DN & 27 & 98 & 8.4 & 3.1 \\
F. L. & 63 & M & 75 & 1.86 & OU & 31 & 78 & 5.7 & 3.6 \\
K. H. & 64 & M & 74 & 1.83 & NSC & 34 & 130 & 13.6 & 3.9 \\
A. S. & 79 & M & 61 & 1.68 & CRFUE & 23 & 110 & 6.6 & 3.4 \\
S. P. & 64 & F & 69 & 1.70 & CRFUE & 29 & 87 & 5.6 & 4.1 \\
A. W. & 65 & F & 80 & 1.81 & CRFUE & 25 & 82 & 8.7 & 4.3 \\
\hline
\end{tabular}

* Hct, hematocrit; BUN, blood urea nitrogen; Creat, serum creatinine; Alb, serum albumin; CGN, chronic glomerulonephritis; DN, diabetic nephropathy; CRFUE, chronic renal failure of unknown etiology; NSC, nephrosclerosis; OU, obstructive uropathy. 
$\mu \mathrm{Ci} / \mathrm{kg}$ ) was given, followed by a continuous infusion of both isotopes $(0.15 \mu \mathrm{Ci} / \mathrm{kg}$ per $\mathrm{h})$. Venous blood samples were obtained without tourniquet occlusion at 30-min intervals for $5 \mathrm{~h}$ while the patient was at absolute bedrest. Alanine (16) and glucose (17) were determined in neutralized perchloric acid extracts of whole blood in triplicate by fluorometric enzymatic techniques. Nonglucose reducing substances, present in higher than normal concentrations in azotemic patients (18), are not measured by this glucosespecific assay which relies upon hexokinase (E.C.2.7.1.1.) and glucose-6-phosphate dehydrogenase (E.C.1.1.1.49). For determination of their specific activities, alanine (5) and glucose (19) were removed from neutralized perchloric acid extracts of blood by ion exchange chromatography. Because of the redistribution of alanine between erythrocytes and plasma in anephric man (20) and to minimize blood loss from the azotemic patients during the study, previously described recovery techniques (15) with plasma were modified for whole blood analysis with small volume samples $(5 \mathrm{ml})$. Glucose recovery was determined for each individual blood sample analyzed and was greater than $95 \%$ in all instances. Alanine recoveries ranged from 93 to $99 \%$. The amount of tritium label from $\left[2{ }^{3} \mathrm{H}\right]$ glucose appearing in the alanine pool was insignificant. Greater than $95 \%$ of ${ }^{14} \mathrm{C}$ label in all blood samples was accounted for by ${ }^{14} \mathrm{C}$ label recovered in the sum of glucose plus alanine.

Turnover rates for both glucose and alanine were calculated for each patient from the plateau portion of each appropriate specific activity curve. Point-to-point calculations of metabolite production and utilization by modifications of the equations of Steele and colleagues were also performed as described previously $(15,21)$. However, because these data did not significantly extend the data derived from the turnover calculations, they have not been included. Calculations of precursor-product interrelationships for alanine and glucose were based upon minor modifications of the equations described by Kreisberg et al. (19). These modifications correct for loss of ${ }^{14} \mathrm{C}$ label appearing in glucose because of fumarase randomization and subsequent decarboxylation by P-enolpyruvate carboxykinase of four-carbon intermediates in the pathway of gluconeogenesis $(22,23)$. Serum insulin was measured by double antibody radioimmunoassay (24). Statistical evaluation of data was performed with Student's $t$ test after ascertaining normal distribution (25). Results are expressed as the mean \pm SEM as the index of dispersion. Computational assistance was provided by the CLINFO project.

\section{RESULTS}

After initiation of the simultaneous isotope infusions, constant specific activity in glucose and alanine was observed in each subject no later than $210 \mathrm{~min}$. In most, constant specific activity was reached between 120 and 150 min. As shown in Figs. 1A and 2A, constant specific activity of the ${ }^{14} \mathrm{C}$ label in the circulating alanine pool was attained after $180 \mathrm{~min}$ of infusion in control subjects and in azotemic patients. In comparison, constant specific activity of ${ }^{3} \mathrm{H}$ label in circulating glucose was evident after 150 and $210 \mathrm{~min}$ in normal volunteers and in patients with chronic renal failure, respectively (Figs. 1C, 2C). The appearance of ${ }^{14} \mathrm{C}$ label in the circulating glucose pool from $\left[\mathrm{U}_{-}{ }^{14} \mathrm{C}\right]$ alanine was determined to provide an index of the rate of gluconeogenesis, at least from alanine. Constant specific activity of the ${ }^{14} \mathrm{C}$ label in glucose was observed by at least 270 min in all control and azotemic subjects (Figs. 1B, 2B). As shown in Table II, mean fasting blood glucose levels of the nondiabetic patients with chronic renal insufficiency were increased $24.3 \%(P=0.005)$ as compared to control subjects, and fasting immunoreactive insulin levels were increased $130 \%(P=0.046)$. None of the nondiabetic azotemic subjects had fasting hyperglycemia (glucose $>6.67 \mathrm{mM}$ ). Calculated glucose turnover in control subjects was found to average 664 $\pm 33.5 \mu \mathrm{mol} / \mathrm{min}$. Glucose turnover was increased $55 \%$ in both the nondiabetic azotemic patients $(P<0.001)$ and in the total group of azotemic patients studied $(P=0.003)$. These increments in the data obtained from the azotemic patients were also statistically significant when expressed either on a per unit weight or body surface basis. Glucose turnover did not correlate
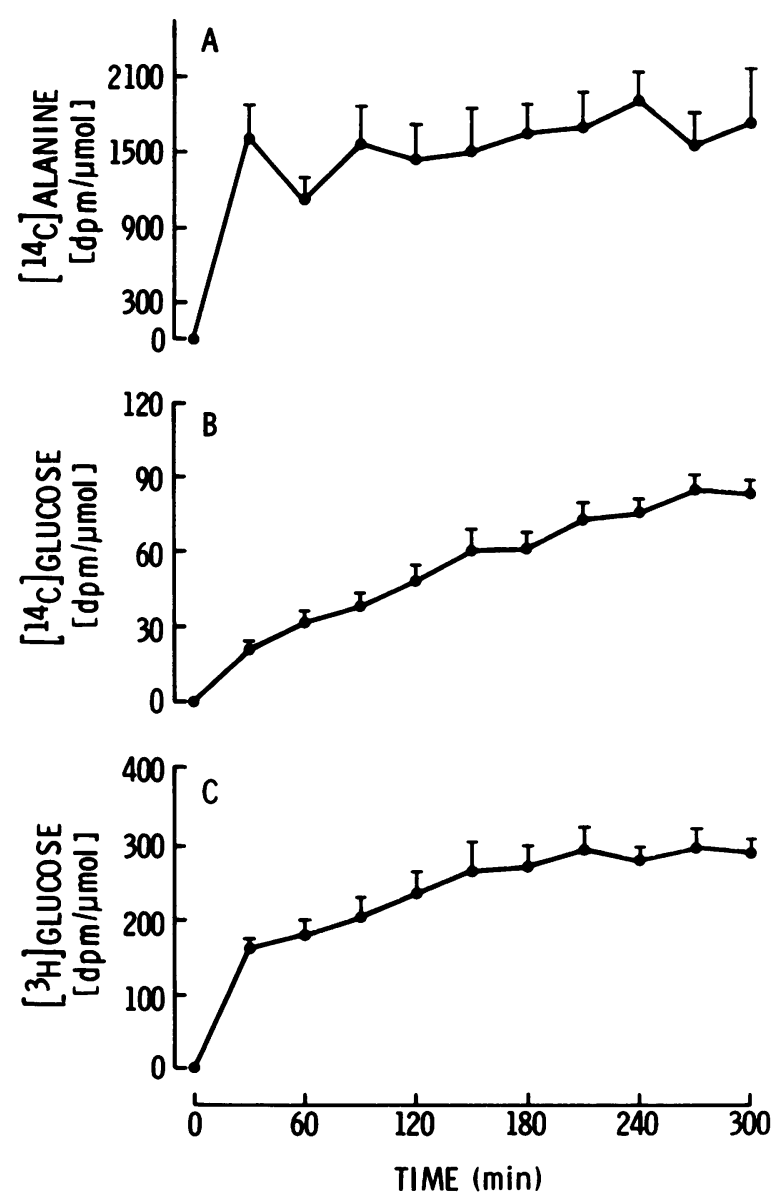

Figure $1{ }^{14} \mathrm{C}$ carbon specific activity in the circulating alanine (A) and glucose (B) pools and tritium specific activity in the circulating glucose pool (C) in 10 control subjects after simultaneous injection-continuous infusions of $\left[\mathrm{U}-{ }^{14} \mathrm{C}\right]$ alanine and $\left[2-{ }^{3} \mathrm{H}\right]$ glucose. Counts per minute were obtained after counting to at least the $1 \%$ significance level. Values are expressed as the mean $\pm S E M$. 

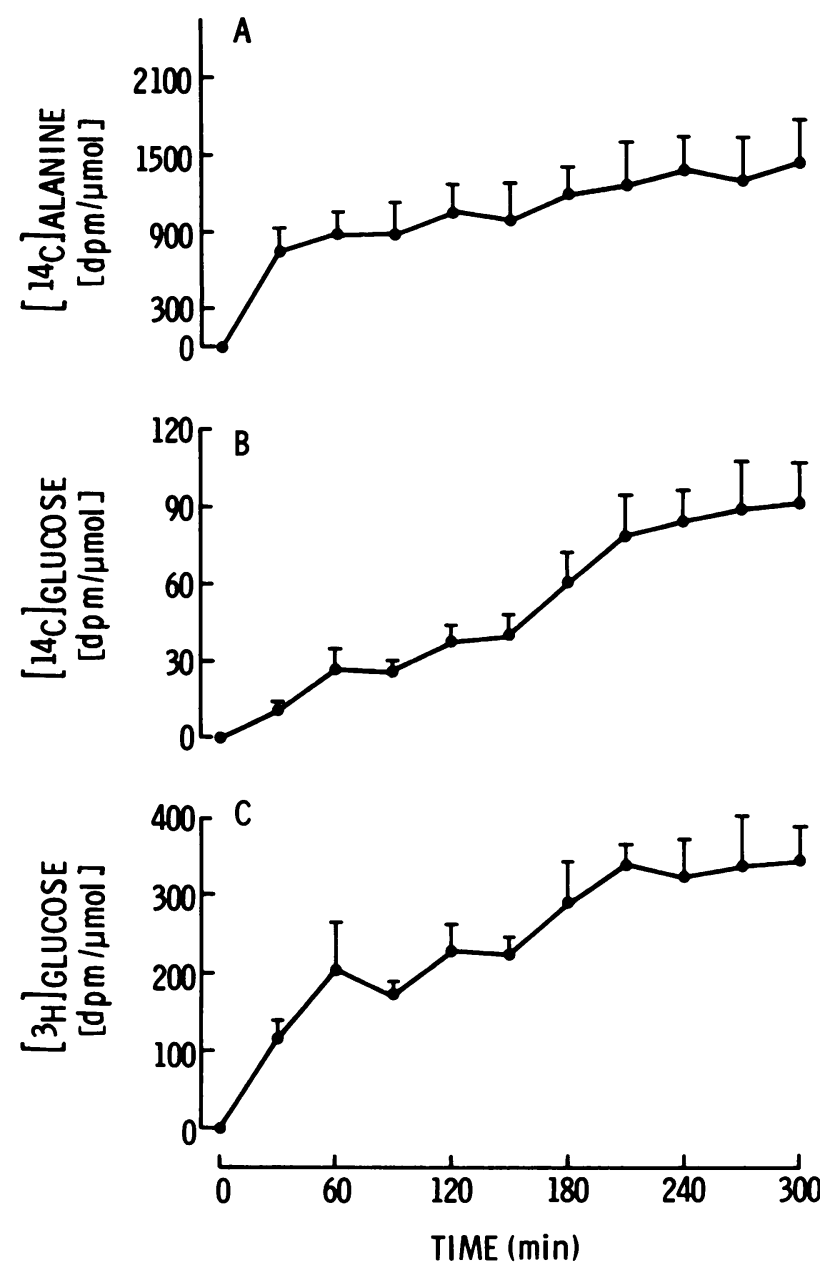

Figure $2{ }^{14} \mathrm{C}$ carbon specific activity in the circulating alanine (A) and glucose (B) pools and tritium specific activity in the circulating glucose pool (C) in 13 azotemic subjects after primed injection-continuous infusions of $\left[\mathrm{U}-{ }^{14} \mathrm{C}\right]$ alanine and $\left[2-{ }^{3} \mathrm{H}\right]$ glucose. Values are expressed as the mean $\pm S E M$ with fasting glucose levels or body surface area in either controls or nondiabetic azotemic subjects, nor did glucose turnover rates correlate with the age of the azotemic subjects studied.

No differences were found in fasting blood alanine levels between the various groups studied (Table III). In control subjects, alanine turnover averaged 163 $\pm 19.4 \mu \mathrm{mol} / \mathrm{min}$. Rates of alanine turnover in the entire azotemic population and in the nondiabetic subpopulation were increased $191 \%(P=0.007)$ and $234 \%(P=0.008)$, respectively. No correlation could be found between age, weight, body surface area, or fasting alanine level and the rate of alanine turnover in either the azotemic or control group.

Glucose production from alanine was estimated by the rate of ${ }^{14} \mathrm{C}$ label appearance in glucose from $\left[\mathrm{U}-{ }^{14} \mathrm{C}\right]$ alanine. In control subjects, glucose produced from alanine was $21.7 \pm 2.24 \mu \mathrm{mol} / \mathrm{min}$, amounting to $3.21 \pm 0.42 \%$ of total glucose production (Table IV). In the nondiabetic azotemic subjects, glucose production from alanine was increased $221 \%(P=0.003)$, whereas in the entire azotemic population the rate of gluconeogenesis was increased $192 \%(P=0.02)$. The relative contribution of gluconeogenesis from alanine to total glucose production was also increased to 9.74 $\pm 3.00 \%(P=0.059)$ in the nondiabetic subjects with chronic renal failure and to $8.64 \pm 2.38 \%(P<0.05)$ in the entire group of azotemic patients. The rate of glucose production from alanine correlated well with the rate of alanine turnover in both control subjects $(r=0.729, P=0.017)$, and the entire azotemic population $(r=0.626, P=0.022)$ as shown in Figs. 3 and 4 , respectively. However, a lesser degree of correlation between rates of gluconeogenesis from alanine and alanine turnover was found in the nondiabetic patients with renal failure $(r=0.597, P=0.069)$.

In control subjects, $40.2 \pm 3.86 \mu \mathrm{mol} / \mathrm{min}$ of alanine were utilized for gluconeogenesis, accounting for 25.4

TABLE II

Glucose Kinetics in Azotemic and Control Subjects

\begin{tabular}{|c|c|c|c|c|c|}
\hline \multirow[t]{2}{*}{ Patients } & \multirow{2}{*}{$\begin{array}{l}\text { Insulin } \\
\mu U / m l\end{array}$} & \multirow{2}{*}{$\begin{array}{c}\text { Glucose } \\
m M\end{array}$} & \multicolumn{3}{|c|}{ Glucose turnover } \\
\hline & & & $\mu \mathrm{mol} / \mathrm{min}$ & $\mu \mathrm{mol} / \mathrm{kg} / \mathrm{min}$ & $\mu \mathrm{mol} / \mathrm{m}^{2} / \mathrm{min}$ \\
\hline Normal volunteers & $6.61 \pm 0.72$ & $4.23 \pm 0.22$ & $664 \pm 33.5$ & $10.3 \pm 0.67$ & $379 \pm 22.6$ \\
\hline \multicolumn{6}{|l|}{ Azotemic subjects } \\
\hline Total & & $6.29 \pm 1.15$ & $1,0.35 \pm 99.3^{*}$ & $14.2 \pm 1.29 \ddagger$ & $563 \pm 52.5^{*}$ \\
\hline Nondiabetics & $15.2 \pm 3.44 \pm$ & $5.26 \pm 0.23 *$ & $1,034 \pm 76.5 \S$ & $14.2 \pm 1.29 \ddagger$ & $5.56 \pm 46.1^{*}$ \\
\hline
\end{tabular}

Values shown are the means \pm SEM for each determination. $P$ represents the probability of rejection of the null hypothesis of equality between the footnoted population mean and the appropriate control mean.

$* P<0.01$.

$\$ P<0.05$.

$\S P<0.001$. 
TABLE III

Alanine Kinetics in Azotemic and Control Subjects

\begin{tabular}{ccccc}
\hline \multicolumn{1}{c}{ Patients } & Alanine & \multicolumn{3}{c}{ Alanine turnover } \\
\hline & $m M$ & $\mu \mathrm{mol} / \mathrm{min}$ & $\mu \mathrm{mol} / \mathrm{kg} / \mathrm{min}$ & $\mu \mathrm{mol} / \mathrm{m}^{2} / \mathrm{min}$ \\
Normal volunteers & $0.233 \pm 0.021$ & $163 \pm 19.4$ & $2.51 \pm 0.29$ & $92.7 \pm 10.7$ \\
& & & & \\
Azotemic subjects & & & & \\
$\quad$ Total & $0.245 \pm 0.019^{*}$ & $474 \pm 96.0 \ddagger$ & $6.47 \pm 1.36 \S$ & $257 \pm 53.1 \ddagger$ \\
Nondiabetic & $0.259 \pm 0.023^{*}$ & $545 \pm 114 \ddagger$ & $7.47 \pm 1.65 \S$ & $295 \pm 64.0 \S$ \\
\hline
\end{tabular}

Values shown are the means \pm SEM for each determination. $P$ represents the probability of rejection of the null hypothesis of equality between the footnoted population mean and the appropriate control mean.

$* P>0.1$.

$\$ P<0.01$.

$\S P<0.05$.

$\pm 1.52 \%$ of total alanine utilization (Table V). In the nondiabetic azotemic patients, alanine utilization for gluconeogenesis was increased $305 \%(P=0.034)$. However, the fraction of total alanine utilization accounted for by gluconeogenesis was unchanged in azotemic subjects as compared to control subjects.

\section{DISCUSSION}

Isotope dilution techniques have been widely used for the in vivo study of intermediary metabolism, particularly of glucose and glucose precursors (26). Simultaneous infusions of labeled glucose and gluconeogenic precursors have been employed previously to obtain accurate data concerning gluconeogenesis in vivo (27). The use of $\left[2-{ }^{3} \mathrm{H}\right]$ glucose provides a relatively good estimation of total glucose production because detritiation occurs by the action of phosphohexoseisomerase (28). However, recent studies have indicated that overestimations of glucose utilization rates result from the use of $\left[2-{ }^{3} \mathrm{H}\right]$ glucose as compared to $\left[3-{ }^{3} \mathrm{H}\right]$ or $\left[6-{ }^{3} \mathrm{H}\right]$ glucose because of futile cycling between glucose and glucose-6-phosphate $(29,30)$. Nevertheless, in a preliminary analysis of our data from another study, ${ }^{1}$ no significant difference could be discerned between the mean rates of glucose turnover determined with $\left[2-{ }^{3} \mathrm{H}\right]$ or $\left[3-{ }^{3} \mathrm{H}\right]$ glucose in normal volunteers $(663 \pm 33.5$ vs. $687 \pm 49.7 \mu \mathrm{mol} / \mathrm{min}$, respectively) or in patients with chronic renal insufficiency $(1034 \pm 86.5$ vs. $1074 \pm 139 \mu \mathrm{mol} / \mathrm{min}$, respectively). With $\left[2-{ }^{-3} \mathrm{H}\right]$ glucose, rates of glucose production observed in the normal volunteers of this study (663 $\mu \mathrm{mol} / \mathrm{min}$ or $172 \mathrm{~g} /$ day) appear to be in excellent agreement with values obtained by others with isotope dilution methods $(8,31)$ or hepatic venous catheterization techniques $(32,33)$. Similarly, the fraction of total glucose production contributed by gluconeogenesis from alanine in the normal subjects of this study (3.21 $\pm 0.42 \%)$ is in good agreement with the data of other studies with isotope techniques $(34,35)$.

${ }^{1}$ S. Rubenfeld and A. J. Garber. Abnormal carbohydrate metabolism in chronic renal failure: suppression of endogenous glucose overproduction by exogenous glucose. Manuscript in preparation.

TABLE IV

Glucose Production from Alanine in Azotemic and Control Subjects

\begin{tabular}{lcccc}
\hline \multicolumn{1}{c}{ Patients } & \multicolumn{3}{c}{ Glucose from alanine } & Glucose from alanine \\
\hline & $\mu \mathrm{mol} / \mathrm{min}$ & $\mu \mathrm{mol} / \mathrm{kg} / \mathrm{min}$ & $\mu \mathrm{mol} / \mathrm{m}^{2} / \mathrm{min}$ & $\%$ \\
Normal volunteers & $21.7 \pm 2.24$ & $0.339 \pm 0.041$ & $12.4 \pm 1.38$ & $3.21 \pm 0.42$ \\
& & & & \\
Azotemic subjects & & & & \\
Total & $63.3 \pm 14.9^{*}$ & $0.888 \pm 0.231^{*}$ & $35.1 \pm 8.71^{*}$ & $8.64 \pm 2.38^{*}$ \\
Nondiabetic & $69.6 \pm 18.9^{*}$ & $0.983 \pm 0.295 \ddagger$ & $38.5 \pm 11.1^{*}$ & $9.74 \pm 3.00 \ddagger$ \\
\hline
\end{tabular}

Values shown are the means \pm SEM for each determination. $P$ represents the probability of rejection of the null hypothesis of equality between the footnoted population mean and the appropriate control mean.

$* P<0.05$.

$\ddagger P=0.059$. 


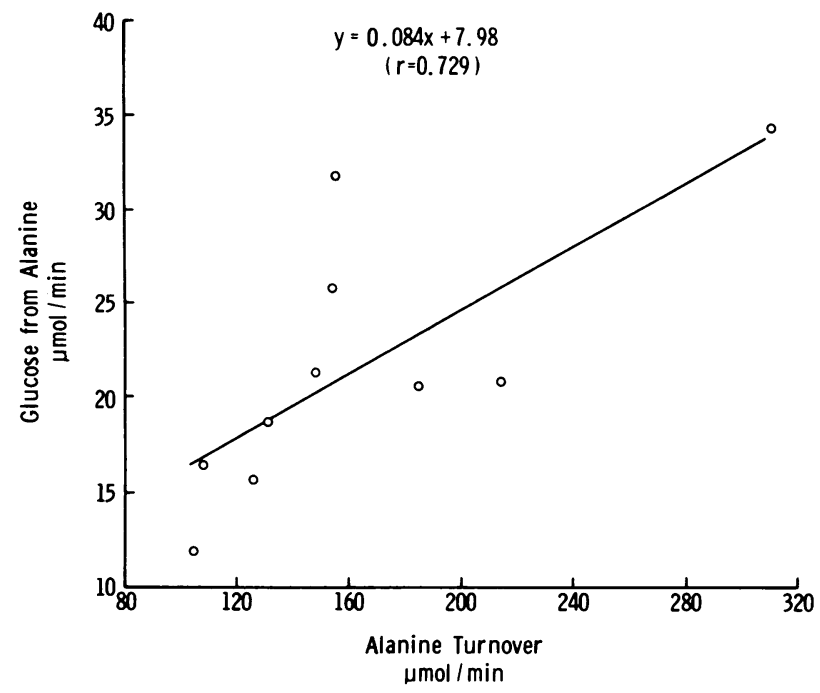

FIGURE 3 Relationships between gluconeogenesis from alanine and alanine turnover rate in 10 control subjects. Each point is the result of a 300 -min primed injection-continuous infusion of $\left[\mathrm{U}-{ }^{14} \mathrm{C}\right]$ alanine and $\left[2-{ }^{3} \mathrm{H}\right]$ glucose in separate patients. The solid diagonal line indicates the least square lines of regresssion.

Although observations concerning glucose and glucose-precursor kinetics in chronic renal failure are previously unreported $(1,36)$, Westervelt observed that insulin-stimulated rates of glucose uptake in forearm studies from azotemic patients were decreased $75 \%$ compared to rates observed with control subjects (37). Decrements in blood glucose concentration after intravenous insulin injection $(2,4,38)$ or tolbutamide injection $(18,38)$ were diminished and slower in development in azotemic as compared to control subjects. In this study, as in other studies, increased fasting immunoreactive insulin levels and normal fasting glucose levels were found in chronic azotemia $(2,3,18,38,39)$. However, the extent to which these

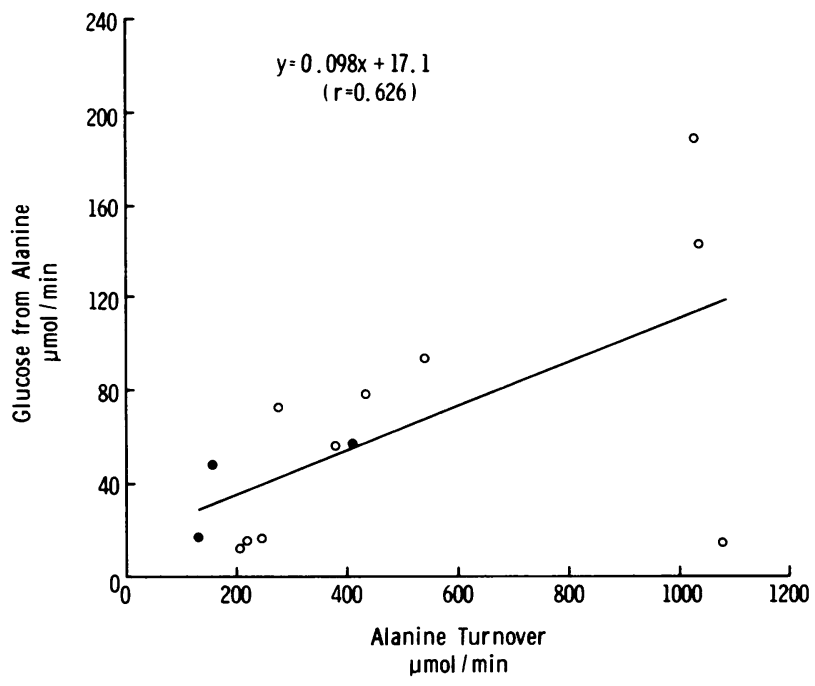

FIGURE 4 Relationship between gluconeogenesis from alanine and alanine turnover rate in 13 azotemic subjects. The open circles represent nondiabetic azotemic patients and the filled circles represent diabetic azotemic patients.

increased immunoreactive insulin levels may reflect the accumulation of proinsulin was not ascertained. The results of previous studies have been interpreted to suggest the presence of insulin resistance in chronic renal failure. The results of this study demonstrate increased basal glucose flux in chronic renal insufficiency. This increased glucose production observed in the postabsorptive state may result in part from an increased rate of gluconeogenesis from alanine because the latter was increased $192 \%$ in the azotemic subjects as compared to control subjects. The increased gluconeogenesis in turn appears to depend in part upon an increased rate of alanine production, without which gluconeogenesis could not be sustained for any significant period. In addition, an independent activation of hepatic alanine metabolism towards gluconeogene-

TABLE V

Alanine Utilization for Gluconeogenesis in Azotemic and Control Subjects

\begin{tabular}{lcccc}
\hline \multicolumn{1}{c}{ Patients } & \multicolumn{3}{c}{ Alanine to glucose } & Alanine to glucose \\
\hline & $\mu$ molimin & $\mu$ mol $/ \mathrm{kg} / \mathrm{min}$ & $\mu \mathrm{mol} / \mathrm{m}^{2} / \mathrm{min}$ & $\%$ \\
Normal volunteers & $40.2 \pm 3.86$ & $0.624 \pm 0.069$ & $22.9 \pm 2.33$ & $25.4 \pm 1.52$ \\
& & & & \\
Azotemic subjects & $143 \pm 39.0^{*}$ & $2.01 \pm 0.600^{*}$ & $79.4 \pm 22.8^{*}$ & $30.1 \pm 4.06 \ddagger$ \\
$\quad \begin{array}{l}\text { Total } \\
\text { Nondiabetics }\end{array}$ & $163 \pm 48.9^{*}$ & $2.31 \pm 0.760 \$$ & $90.6 \pm 28.8^{*}$ & $29.3 \pm 5.20 \ddagger$ \\
\hline
\end{tabular}

Values shown are the means \pm SEM for each determination. $P$ represents the probability of rejection of the null hypothesis of equality between the footnoted population mean and the appropriate control mean.

$* P<0.05$.

$+P>0.1$.

$\S P=0.055$. 
sis must also be present because the percentage of total glucose production contributed by gluconeogenesis was increased $169 \%$ in azotemic subjects, and because alanine levels were unchanged despite a threefold increase in alanine delivery. In normals, increased alanine delivery as provided by an alanine infusion results in increased alanine levels (40). These findings of increased gluconeogenesis in azotemic man correlate well with findings of increased in vitro hepatic gluconeogenesis in the uremic rat $(12,13)$.

The total increment in glucose production observed in patients with chronic renal failure cannot be accounted for entirely by the increased rate of gluconeogenesis from alanine. Although not specifically determined in this study, glucose production from precursors such as glycerol, lactate, and other amino acids may also be increased. Even so, it seems unlikely that increased gluconeogenesis alone can produce the entire elevation in glucose production because the uptake of all glucose precursors accounts for only about $25 \%$ of hepatic glucose production in postabsorptive normal man (41), and only $32 \%$ in diabetic man (42). Because total glucose production in azotemic subjects was increased by more than $50 \%$, some element of increased glucogenolysis as well as increased gluconeogenesis seems likely.

The data of the present study suggest that an insensitivity or resistance to the metabolic action of insulin may be an important mechanism in the abnormal glucose and glucose-precursor kinetics observed in chronic renal insufficiency. The findings of elevated immunoreactive insulin levels together with increased glycogenolysis and gluconeogenesis suggest an insensitivity to insulin modulation or hepatic glucose production. The demonstration of diminished insulin binding to hepatic membranes isolated from experimentally uremic rats suggests a potential mechanism for the hepatic insulin insensitivity because diminished receptor binding may produce diminished hormone action (43). Additionally, impaired insulin action on skeletal muscle may account for the increased alanine turnover observed in patients with chronic renal insufficiency. Because the action of insulin is important to the regulation of both protein synthesis and protein degradation in skeletal muscle (44), insensitivity or resistance to insulin might be associated with either accelerated muscle proteolysis or diminished amino acid incorporation into muscle protein or both. As a consecquence of either process, accelerated alanine formation and release would be anticipated (45). These findings of increased alanine production in postabsorptive azotemic man extend our prior observations of increased skeletal muscle alanine formation and release observed in muscle preparations from experimentally uremic rats (11). An impairment of insulin-mediated glucose utilization may also be inferred from the data of this study. Mean fasting im- munoreactive insulin levels were increased $130 \%$ and mean fasting glucose levels were increased $20 \%$ in azotemic subjects. These findings, coupled with the observation of a $56 \%$ increase in glucose flux, suggest an impairment of glucose disposal. Otherwise, unchanged glucose levels would be anticipated despite the substantial increments in glucose flux.

Although an insensitivity or resistance to insulin action can account for most of the derangements in glucose and glucose-precursor kinetics observed in azotemic subjects, abnormalities in the action and circulating levels of other hormones have also been reported in chronic renal insufficiency. Glucagon enhances both hepatic alanine extraction and gluconeogenesis (34). Because increased circulating glucagon levels, including the $3,500 \mathrm{~mol}$ wt fraction, have been reported in chronic renal failure (39), pathologic hyperglucagonemia may account in part for the increased gluconeogenesis observed in azotemic man. Parathyroid hormone, like glucagon, appears to stimulate hepatic adenylate cyclase activity (46) and hepatic gluconeogenesis from three carbon precursors (47). Whereas the effect of parathyroid hormone on adenylate cyclase activity is less than the stimulation produced by epinephrine or glucagon, parathyroid hormone levels are substantially elevated in chronic renal failure (36) and may contribute to the increased hepatic gluconeogenesis. However, a single study has suggested that parathyroidectomy has no effect upon the abnormal glucose metabolism of chronic renal failure (48).

In summary, the findings of the present study demonstrate increased glucose production, utilization, and gluconeogenesis in patients with chronic renal failure. Increased glucose production from alanine appears to derive from a primary abnormality of hepatic glucose metabolism. Rates of alanine production also were substantially increased suggesting an independent abnormality of alanine metabolism in peripheral tissues such as skeletal muscle. Relative elevations of fasting glucose and immunoreactive insulin levels were observed in azotemic patients. Taken as a whole, the findings of increased alanine production, increased glucose production, increased gluconeogenesis, and impaired glucose disposal, all of which are processes regulated by insulin, suggest an underlying hepatic as well as peripheral insensitivity to insulin action in chronic renal insufficiency.

\section{ACKNOWLEDGMENTS}

We are indebted to Nurit Shimoni, Carol Maillet, Sherry Barlow, and Lance Sindo for excellent technical assistance. The advice and commentary of Dr. Wadi Suki is gratefully acknowledged. We are also indebted to Doctors Charles Crumb, Edward Weinman, and Carmelo Dichoso for referral of their patients for this study.

The research for this report was supported in part by 
contract AM-4-2215 from the Artificial Kidney-Chronic Uremia Program; by the CLINFO Project, contract RR-52218; grant RR-0350 from the Division of Research Resources, National Institutes of Health; and by a grant from the Kelsey-Leary Foundation.

\section{REFERENCES}

1. DeFronzo, R. A., R. Andres, P. Edgar, and W. G. Walker. 1973. Carbohydrate metabolism in uremia: a review. Medicine (Baltimore). 52: 469-481.

2. Horton, E. S., C. Johnson, and H. E. Lebevitz. 1968. Carbohydrate metabolism in urea. Ann. Intern. Med. 68: 63-74.

3. Lowrie, E. G., J. S. Soeldner, C. L. Hampers, and J. P. Merrill. 1970. Glucose metabolism and insulin secretion in uremic, pre-diabetic, and normal subjects. J. Lab. Clin. Med. 76: 603-615.

4. Perkoff, G. T., C. L. Thomas, J. D. Newton, J. C. Sellman, and F. H. Tyler. 1958. Mechanisms of impaired glucose tolerance in uremia and experimental hyperazotemia. Diabetes. 7: 375-383.

5. Garber, A. J., D. M. Bier, P. E. Cryer, and A. S. Pagliara. 1974. Hypoglycemia in compensated chronic renal insufficiency: substrate limitation of gluconengenesis. Diabetes. 23: $982-986$.

6. Frizzell, M., P. R. Larsen, and J. B. Field. 1973. Spontaneous hypoglycemia associated with chronic renal failure. Diabetes. 22: 493-498.

7. Runyan, J. W., D. Hurwitz, and S. L. Robbins. 1955. Effect of Kimmelstiel-Wilson syndrome on insulin requirements in diabetes. N. Engl. J. Med. 252: 385-391.

8. Bowen, H. F., and J. A. Moorhouse. 1973. Glucose turnover and disposal in maturity-onset diabetes. $J$. Clin. Invest. 52: 3033-3045.

9. Felig, P., T. Pozefsky, E. Marliss, and G. F. Cahill, Jr. 1970. Alanine: key role in gluconeogenesis. Science (Wash. D. C.). 167: 1003-1004.

10. Wahren, J., P. Felig, E. Cerasi, and R. Luft. 1972. Splanchnic and peripheral glucose and amino acid metabolism in diabetes mellitus. J. Clin. Invest. 52: 1870-1878.

11. Garber, A. J. 1977. Skeletal muscle alanine and glutamine formation and release in experimental uremia. Clin. Res. 52: 32A. (Abstr.)

12. Frohlick, J., J. Scholmerich, G. Hoppe-Seyler, K. P. Maier, H. Talke, P. Schollmeyer, and W. Gerok. 1974. The effect of acute uremia on gluconeogenesis in isolated perfused rat livers. Euro. J. Clin. Invest. 4: 453-458.

13. Dzurik, R., T. R. Niederland, and P. Cernacek. 1969. Carbohydrate metabolism by rat liver slices incubated in serum obtained from uremic patients. Clin Sci. (Oxf.). 37: 409-417.

14. Fajans, S. S., and J. W. Conn. 1959. The early recognition of diabetes mellitus. Ann. N. Y. Acad. Sci. 82: 208-218.

15. Garber, A. J., P. E. Cryer, J. V. Santiago, M. W. Haymond, A. S. Pagliara, and D. M. Kipnis. 1976. The role of adrenergic mechanisms in the substrate and hormonal response to insulin-induced hypoglycemia in man. $J$. Clin. Invest. 58: 7-15.

16. Karl, I. E., A. S. Pagliara, and D. M. Kipnis. 1972. A microfluorometric enzymatic assay for the determination of alanine and pyruvate in plasma and tissues. J. Lab. Clin. Med. 80: 434-441.

17. Lowry, O. H., and J. V. Passoneau. 1972. A Flexible System of Enzymatic Analysis. Academic Press, Inc., New York. 174-177.
18. Cerletty, J. M., and N. H. Enbring. 1967. Azotemia and glucose intolerance. Ann. Intern. Med. 66: 1097-1108.

19. Kriesberg, R. A., A. M. Siegal, and W. C. Owen. 1971. Glucose-lactate interrelationships: Effect of ethanol. J. Clin. Invest. 50: 175-185.

20. Ganda, O. P., T. T. Aoki, J. S. Soeldner, R. S. Morrison, and G. F. Cahill, Jr. 1976. Hormone-fuel concentrations in anephric subjects. Effects of hemodialysis (with special reference to amino acids). J. Clin. Invest. 57: 1403-14011.

21. Steele, R., H. Rostami, and N. Altszuler. 1974. A twocompartment calculator for the dog glucose pool in the nonsteady state. Fed. Proc. 33: $1869-1876$.

22. Walter, P., V. Paetkau, and H. A. Lardy. 1966. Paths of carbon in gluconeogenesis and lipogenesis. III. The role and regulation of mitochondrial processes involved in supplying precursors of phosphoenolpyruvate. J. Biol. Chem. 241: 2523-2532.

23. Hanson, R. W., and A. J. Garber. 1972. Phosphoenolpyruvate carboxykinase. I. Its role in gluconeogenesis. Am. J. Clin. Nutr. 24: 1010-1021.

24. Hales, C. N., and P. J. Randle. 1963. Immunoassay of insulin with insulin-antibody precipitate. Biochem. J. 88: $137-146$.

25. Bahn, A. K. 1972. Basic Medical Statistics. Grune and Stratton, Inc., New York. 136-143.

26. Searle, G. L. 1976. The use of isotope turnover techniques in the study of carbohydrate metabolism in man. Clin. Endocrinol. Metab. 5: 783-804.

27. Chiasson, J. L., J. E. Liljenquist, W. W. Lacy, A. S. Jennings, and A. D. Cherrington. 1977. Gluconeogenesis: Methodological approaches in vivo. Fed. Proc. 36: 22.9235.

28. Katz, J., and A. Dunn. 1967. Glucose-2-t as a tracer for glucose metabolism. Biochemistry. 6: 1-5.

29. Katz, J., H. Tostami, and A. Dunn. 1974. Evaluation of glucose turnover, body mass and recycling with reversible and irreversible tracers. Biochem. J. 142: 161170.

30. Katz, J., A. Dunn, M. Chenoweth, and S. Golden. 1974. Determination of synthesis, recycling and body mass of glucose in rats and rabbits in vivo with ${ }^{3} \mathrm{H}$ - and ${ }^{14} \mathrm{C}$ labelled glucose. Biochem. J. 142: 171-183.

31. Paul, P., and W. M. Bortz. 1969. Turnover and oxidation of plasma glucose in lean and obese humans. Metab. Clin. Exp. 18: 570-584.

32. Wahren, J., P. Felig, G. Ahlborg, and L. Jorfeldt. 1971. Glucose metabolism during leg exercise in man.J. Clin. Invest. 50: 2715-2725.

33. Wahren, J., P. Felig, and L. Hagenfeldt. 1976. Effect of protein ingestion on splanchnic and leg metabolism in normal man and in patients with diabetes mellitus. $J$. Clin. Invest. 57: 987-999.

34. Chiasson, J. L., J. E. Liljenquist, B. C. Sinclair-Smith, and W. W. Lacy. 1975. Gluconeogenesis from alanine in normal postabsorptive man: intrahepatic simulatory effect of glucagon. Diabetes. 24: 574-584.

35. Chochinov, R. H., and J. A. Moorhouse. 1972. Alanine and gluconeogenesis in health and diabetes. Diabetes. 21:(Suppl. 1): $341-342$.

36. Feldman, H. A., and I. Singer. 1974. Endocrinology and metabolism in uremia and dialysis. A clinical review. Medicine (Baltimore). 54: 345-376.

37. Westervelt, F. B. 1979. Uremia and insulin response. Arch. Intern. Med. 126: 865-869.

38. Spitz, M. M., A. H. Rubenstein, I. Bersohn, C. Abrahams, and C. Lowry. 1970. Carbohydrate metabolism in renal disease. Q. J. Med. 39: 201-226.

39. Sherwin, R. S., C. Gastl, F. O. Finkelstein, M. Fisher 
H. Black, R. Hendler, and P. Felig. 1976. Influence of uremia and hemodialysis on the turnover and metabolic effects of glucagon. J. Clin. Invest. 57: 722-731.

40. Pagliara, A. S., I. E. Karl, D. C. DeVivo, R. D. Feigin, and D. M. Kipnis. 1972. Hypoalaninemia: a concomitant of ketotic hypoglycemia. J. Clin. Invest. 51: 1440-1449.

41. Felig, P. 1973. The glucose-alanine cycle. Metab. Clin. Exp. 22: 407-413.

42. Wahren, J., P. Felig, E. Cerasi, and R. Luft. 1972. Splanchnic and peripheral glucose and amino acid metabolism in diabetes mellitus. J. Clin. Invest. 51: 1870-1878.

43. Soman, V., and P. Felig. 1977. Glucagon and insulin binding to liver membranes in a partially nephrectomized uremic rat model. J. Clin. Invest. 60: 224-232.

44. Fulks, R. M., K. B. Li, and A. L. Goldberg. 1975. Effects of insulin, glucose, and amino acids on protein turnover in rat diaphragm. J. Biol. Chem. 250: 290-298.

45. Jefferson, L. S., D. E. Rannels, B. L. Munger, and H. E. Morgan. 1974. Insulin in the regulation of protein turnover in heart and skeletal muscle. Fed. Proc. 33: 1098-1104.

46. Canterbury, J. M., G. Levy, E. Ruiz, and E. Reiss. 1974. Parathyroid hormone activation of adenylate cyclase in liver. Proc. Soc. Exp. Biol. Med. 147: 366-370.

47. Moxley, M. A., N. H. Bell, S. R. Wagle, D. O. Allen, and J. Ashmore. 1974. Parathyroid hormone stimulation of glucose and urea production in isolated liver cells. Am. J. Physiol. 227: 1058-1061.

48. Amend, W. J. C., Jr., S. M. Steinberg, E. G. Lowrie, J. M. Lazarus, J. S. Soeldner, C. L. Hampers, and J. P. Merrill. 1975. The influence of serum calcium and parathyroid hormone upon glucose metabolism in uremia. J. Lab. Clin. Med. 86: 435-444. 